\title{
Internet of Things (loT) based outdoor performance characterisation of solar photovoltaic module
}

\author{
Paresh S. Nasikkar ${ }^{l,}$, and Javed K. Sayyad ${ }^{l}$ \\ ${ }^{1}$ Symbiosis Institute of Technology, Symbiosis International (Deemed University), Lavale, Pune, 412115 MH (India).
}

\begin{abstract}
Outdoor performance characterisation of the Solar Photovoltaic (SPV) module is essential to while designing and commissioning a new SPV power plant. The health of SPV plant is monitored using a conventional method which underutilises the workforce and resources used for Operation and Maintenance (O\&M) of the SPV power plant. Outdoor performance characterisation of SPV module using reliable, compact, portable, and economical Current-Voltage (I-V) curve tracer having IoT capability and auto sweep capability is presented in this paper. The capacitive load method is used for I-V curve sweep, and the result is compared with the resistive load method. In this paper, the advantages of using a capacitive load method over resistive load method are observed and experimentally validated. The ease of using IoT feature makes this proposed I-V Curve Tracer (IVCT) device more reliable to trace Current-Voltage (I-V) curve and Power-Voltage (P-V) curve for outdoor performance characterisation of SPV module.
\end{abstract}

\section{INTRODUCTION}

Limited availability of fossil fuel, cost effectiveness due technology upgradation in SPV panel manufacturing and consumer awareness towards use of green technology has exponentially increases the use of SPV. Globally growing need of energy can be fulfilled by grid tied SPV power plant [1]. It can be easily generated and used in household, commercial and industrial applications [2]. The major disadvantage of commercially available SPV module is its low conversion efficiency $(\eta<20 \%)$ and the non-linearity of the output I-V curve $[3,4]$.

Commissioning the SPV power plant on the remote location where unshaded space is largely available is the prime concern of the power plant design engineer [5]. Performance analysis and continuous monitoring of this power plant during operation is the necessity now a day. It adds financial burden over power plant owner. More accurate power plant monitoring system helps to schedule regular maintenance which will increase life span of the power plant [6]. It also helps to find faults during operation because of uncertain change in metrological parameters [7-9]. Internet of Things (IoT) based outdoor performance characterisation is the necessity to monitor the plant continuously from remote location [10].

In this paper analysis of SPV system is evaluated using IoT based I-V Curve Tracer (IVCT). This developed IVCT device with capacitive load method gives high degree of flexibility and scalability in comparison with resistive load is shown and validated experimentally.

\subsection{Performance Characterisation of SPV Module}

Tracing I-V and P-V curve for performance characterisation is predominant method than other existing method. These curve help to extract important electrical parameters like short circuit current $\left(\mathrm{I}_{\mathrm{sc}}\right)$, open circuit voltage $\left(\mathrm{V}_{\mathrm{oc}}\right)$, maximum current $\left(\mathrm{I}_{\mathrm{m}}\right)$, maximum voltage $\left(\mathrm{V}_{\mathrm{m}}\right)$, maximum power $\left(\mathrm{P}_{\mathrm{m}}\right)$, series resistance $\left(R_{s}\right)$, shunt resistance $\left(R_{s h}\right)$, field factor $(F F)$, efficiency $(\eta)$ etc. which shown in Fig. 1 [11].

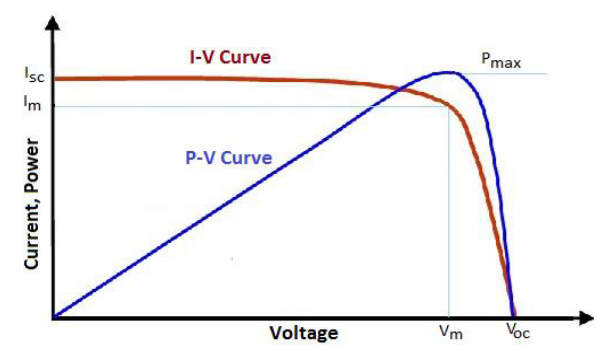

Fig. 1. $I-V$ and $P-V$ curve

Conventionally for curve tracing, SPV module is loaded from zero resistance path to infinite resistance path using variable resistance. SPV module is active device it generates energy and IVCT device acts as load which sweeps curve using internal load circuitry.

*Corresponding author: paresh.nasikkar@sitpune.edu.in 
Conductivity of silicon material increases as increases in solar irradiance makes SPV module to generate more current at output. For change in temperature, the series resistance increases which makes more voltage drop across series resistance and less voltage at output of SPV module.

\section{PROPOSED TECHNIQUE FOR IVCT}

Major building blocks of the proposed IVCT device is SPV modules, Sensor, load Unit and Raspberry Pi 3B model as a central processing unit. Detailed block diagram of proposed IVCT is shown in Fig. 2.

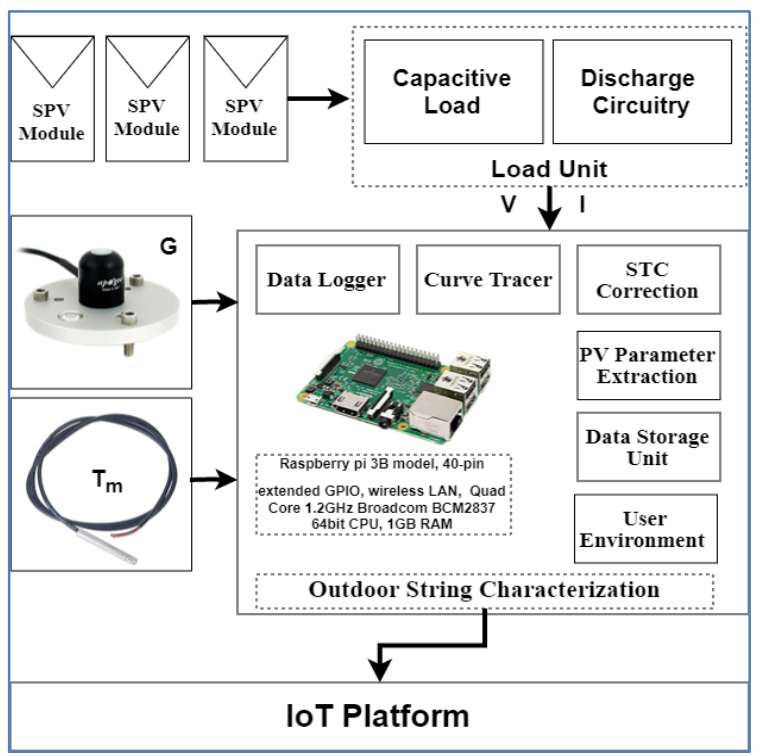

Fig. 2. Detailed block diagram of Proposed IVCT

\subsection{SPV Module}

Eight SPV modules were installed on the terrace of the solar photovoltaic lab for testing designed IVCT. These modules are manufactured by Akshaya solar power Pvt. Ltd. and there STC technical specifications electrical characteristics are as tabulated in Table 1. For this research ASP-12-60 $\mathrm{W}_{\mathrm{p}}$ SPV modules is the device under test and installed on terrace as shown in Fig. 3.

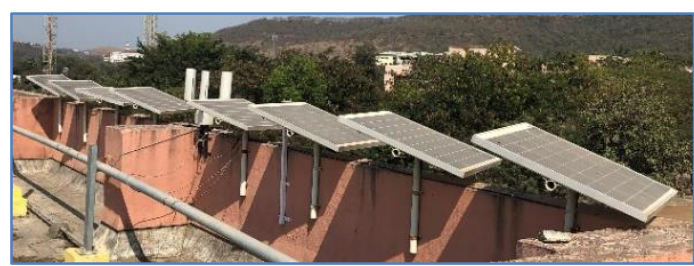

Fig. 3. ASP-12-60 $\mathrm{W}_{\mathrm{p}}$ installed on terrace of SPV Lab

Table 1: Technical specification of ASP-12-60 $\mathrm{W}_{\mathrm{p}}$

\begin{tabular}{|c|l|c|}
\hline Symbol & Parameter & Value \\
\hline $\mathrm{P}_{\max }$ & Maximum Power & $60 \mathrm{~W}_{\mathrm{p}}$ \\
\hline $\mathrm{V}_{\max }$ & Maximum Voltage & $17.6 \mathrm{~V}$ \\
\hline $\mathrm{I}_{\max }$ & Maximum Current & $3.41 \mathrm{~A}$ \\
\hline $\mathrm{V}_{\mathrm{oc}}$ & Open Circuit Voltage & $21.5 \mathrm{~V}$ \\
\hline
\end{tabular}

\begin{tabular}{|c|l|c|}
\hline $\mathrm{I}_{\mathrm{sc}}$ & Short Circuit Current & \multicolumn{1}{|c|}{$3.68 \mathrm{~A}$} \\
\hline$\alpha$ & Temperature coefficient of $\mathrm{I}_{\mathrm{sc}}$ & $+0.0009 /{ }^{\circ} \mathrm{C}$ \\
\hline$\beta$ & Temperature coefficient of $\mathrm{V}_{\mathrm{oc}}$ & $-0.004 /{ }^{\circ} \mathrm{C}$ \\
\hline
\end{tabular}

\subsection{Sensors}

In order to obtain correct measurement of voltages during operation, the SPV panel voltage needs to be divided which is accomplished by a resistive voltage divider circuit. This provides voltage isolation and protects other circuitry. This voltage is then read by the external 12 bit analog to digital converter ADS1015 and send back to raspberry pi.

DC Current can be measured using small shunt resistor or different current sensors like ADS712, LEM DC current transducer DK 20 C5 U etc. [12]. We have used ACS712 IC based hall effect current sensor which is cost effective and easily available. ACS712 has 3 variants, 5A, 20A, 30A having different current measuring capability. This sensor is bidirectional and can sense current in both directions. With no load connected sensor shows $2.5 \mathrm{~V}$ at the output pin. Sensitivity of ACS712 $5 \mathrm{~A}$ is $185 \mathrm{mV} / \mathrm{A}$. This signal is directly feed to external ADC1015 which converts analog signal to digital and send it to the Raspberry pi.

For light irradiance measuremtes, Apogee SP110SS pyranometer sensor is used. It is calibrated by manufacturer and it has sensitivity $0.2 \mathrm{mV} / \mathrm{Wm}^{-2}$. This senor is aligned with SPV module to measure light irradiance accurately as shown in Fig. 4. DS18B20 temperature sensor is placed backside of the SPV module to measure of module temperature continuously.

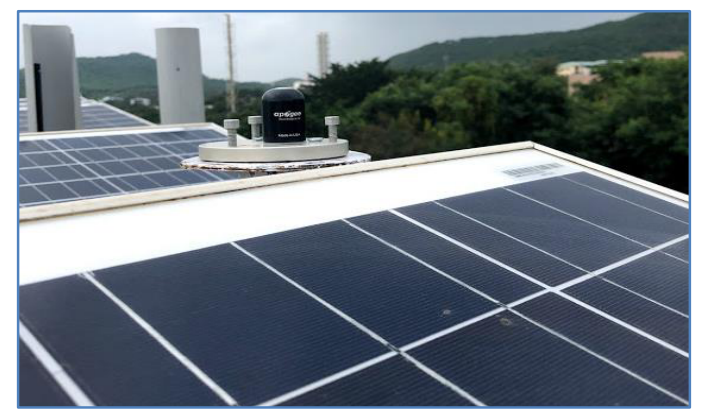

Fig. 4. Apogee SP110SS Pyranometer on terrace

\subsection{Load Unit}

\subsubsection{Capacitive Load}

To obtain characterisation curves, it is important to control the current generated by the SPV module. To perform this, one has to vary resistance (load) over entire range in a short span of time $T_{\text {scan }}$ from zero to infinity. It will measure the points of the I-V curve from the shortcircuit current to the open-circuit voltage. This research uses one of the methods to emulate as a variable resistance is by using capacitor as a load. Results for the resistive load is also taken to validate the results. Capacitor load provides natural sweep and able to 
perform well under Partial shading condition (PSC) [1315]. Capacitive method is useful to develop I-V curve tracer for high power rated photovoltaic modules.

\subsubsection{Discharge Circuitry}

To start the new sweep, charged capacitor during curve tracing need to be discharged first for accurate measurement. It requires resistive (energy sink) elements to discharge capacitor safely within a short span of time. We have used heat sinkable resistor which has Aluminium Housed direct heat sink mooting. Five resistors of $300 \mathrm{ohm}, 100 \mathrm{~W}$ specification is used in series or parallel as per requirement to safely discharge the capacitor before and after I-V curve tracing is shown in Fig. 5.

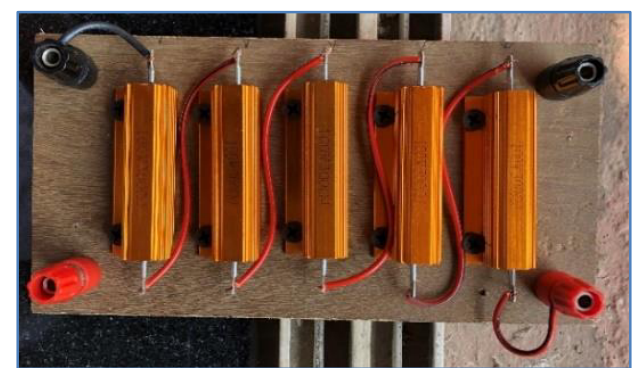

Fig. 5. Heat Sinkable High Wattage Resistor

Total time duration required to discharge the capacitor $(\tau)$ safely is given by Equation 1 [16]

$\tau=5 * \mathrm{R} * \mathrm{C}$

\subsection{Raspberry Pi 3B as Central Processing Device}

The Raspberry Pi 3B was programmed with python programming to monitor both the current and the voltage of the SPV module. Real time measurement of metrological parameters like light radiance and module temperature is measured using sensor and used for STC correction. Flow chart of the proposed device working is as given in Fig. 6. Clear sky condition is checked using light irradiance data to start the device.

\subsubsection{Modifying measured parameters to STC condition at varying temperature and light irradiance (STC correction)}

Impact of varying meteorological parameters will give the erroneous reading of instantaneous current and voltage. To reduce the effect, measured electrical parameters need to be corrected with STC conversion [8, 17]. STC conversion for of measured parameters are calculated using Equation 2 and 3 which are given below,

$V_{S T C}=V_{\text {meas }}\left\{1+\left[\beta * \ln \left(\frac{G_{\text {STC }}}{G_{\text {meas }}}\right)+\left[\beta *\left(T_{S T C}-T_{\text {meas }}\right)\right]\right]\right\}$

$$
I_{S T C}=I_{\text {meas }}\left\{1+\left[\alpha *\left|\left(T_{S T C}-T_{\text {meas }}\right)\right| *\left(\frac{G_{S T C}}{G_{\text {meas }}}\right)\right]\right\}
$$

Where, $V_{S T C}$ and $I_{S T C}$ is voltage and current at STC (labelled specification) respectively, $V_{\text {meas }}$ and $I_{\text {meas }}$ is the voltage and current measured during I-V tracing respectively, $G_{S T C}$ is the light irradiance at STC $\left(1000 \mathrm{~W} / \mathrm{m}^{2}\right), T_{S T C}$ is module temperature at STC $\left(25^{\circ} \mathrm{C}\right)$, $G_{\text {meas }}$ and $T_{\text {meas }}$ is the light irradiance and module temperature measured using pyranometer and temperature senor during I-V sweep respectively, $\alpha$ and $\beta$ is the thermal coefficient of the short-circuit current $\left(\mathrm{V} /{ }^{\circ} \mathrm{C}\right)$ and thermal coefficient of the open-circuit voltage $\left(\mathrm{A} /{ }^{\circ} \mathrm{C}\right)$ respectively.

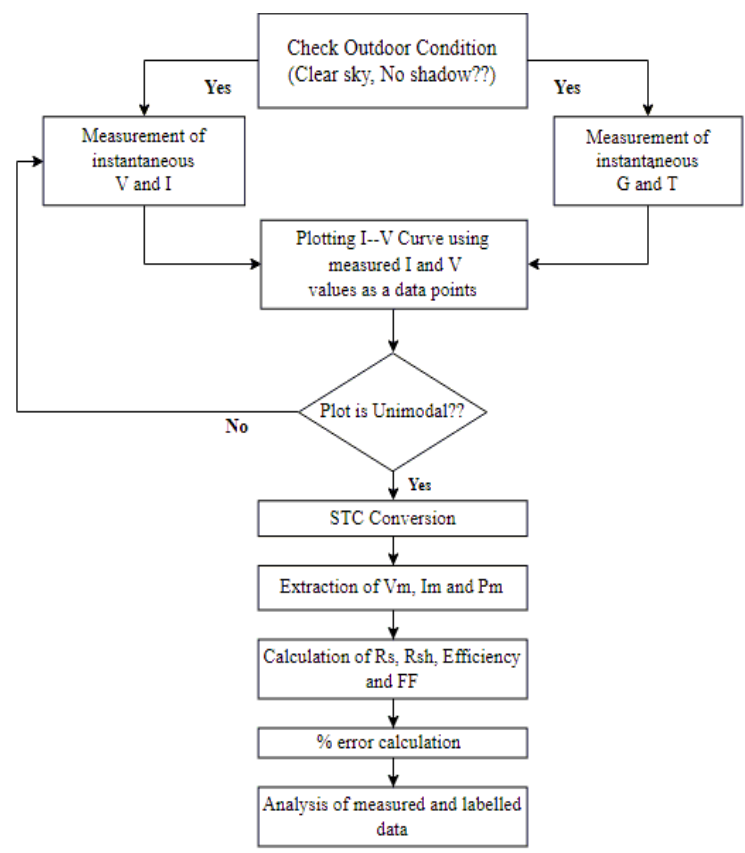

Fig. 6. Flow chart of python program

\subsubsection{Data Logger}

The instantaneous values of $\mathrm{I}, \mathrm{V}, \mathrm{G}$, and $\mathrm{T}_{\mathrm{m}}$ can be feed directly to external ADS1015 for data conversion from analog to digital. This Digital data is given to Raspberry pi which acts as central processing unit in the proposed IVCT device.

Measurement of high current and high voltage requires proper isolation during measurement. Galvanic isolation is used to protect main circuitry and Raspberry pi microprocessor from unwanted surge and high current due to short circuit. It will also help to reduce noise and provide safety for technician/engineer during performance characterisation.

\section{RESULT AND DISCUSSION}

Fig. 7 shows the actual hardware test setup in the SPV research lab. The reference values specified by the manufacturer on the back side of the SPV module are utilized in the analysis for error and accuracy calculation. 


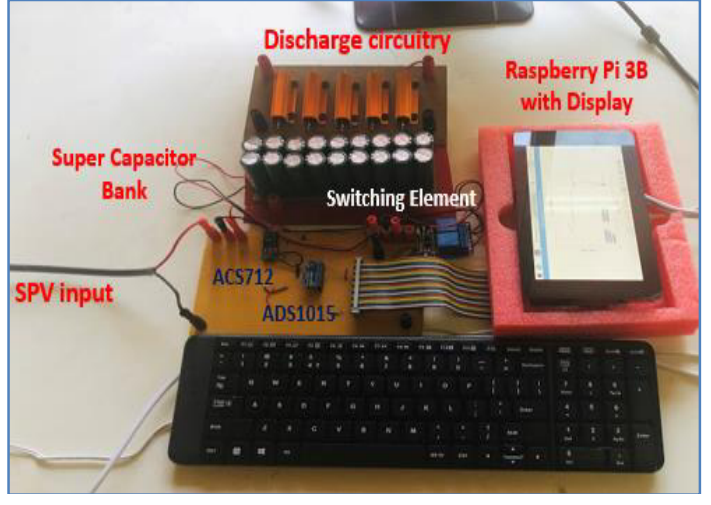

Fig. 7. Actual Hardware of Proposed IVCT

\subsection{Result of conventional method (R Load)}

Conventional $\mathrm{R}$ load method is tested and measurement has been taken out for validation. Rheostat of $300 \mathrm{ohm}$ is used as resistive load to vary load resistance from minimum to maximum manually. This method is simple, cost-effective and shows significant results for low operating solar power modules. But this method has certain limitations. It unable to track fast changing (nonuniform) operating and climatic condition. For large operating power, resistances become heavy, bulky and costly [18-20]. For power solar modules resistive load shows inherent losses and dissipates heats during operation [20].

Throughout all the analysis of $\mathrm{R}$ load, the sample frequency is depending on the operator expertise. SPV module electrical parameters extracted from captured I$\mathrm{V}$ and P-V curve of ASP 12-60Wp on different time instants on the same day is tabulated in Table 2,3,4.

Table 2: Result analysis for 12:00PM Time stamp

\begin{tabular}{|c|c|c|c|c|}
\hline $\begin{array}{c}\text { Time } \\
\text { Stamp }\end{array}$ & \multicolumn{4}{|c|}{$12: 00$} \\
\hline $\begin{array}{c}\text { Parameter } \\
\text { s }\end{array}$ & Measured & $\begin{array}{c}\text { STC } \\
\text { Corrected } \\
\end{array}$ & $\begin{array}{c}\% \\
\text { Error }\end{array}$ & $\begin{array}{c}\% \\
\text { Accuracy } \\
\end{array}$ \\
\hline$V_{o c}(V)$ & 20.7 & 21.998 & 2.3 & 97.7 \\
\hline$V_{\text {max }}(V)$ & 14 & 14.878 & 18.3 & 81.7 \\
\hline $\mathbf{I}_{\mathrm{sc}}(\mathrm{A})$ & 3.67 & 3.5966 & 2.3 & 97.7 \\
\hline$I_{\max }(A)$ & 3.49 & 3.4202 & 0.3 & 99.7 \\
\hline$P_{\max }\left(W_{p}\right)$ & 48.86 & 50.886 & 17.9 & 82.1 \\
\hline $\begin{array}{c}\mathbf{G}_{\text {meas }} \\
\left(\mathbf{W} / \mathbf{m}^{2}\right)\end{array}$ & 720 & & & \\
\hline $\mathbf{T}_{\text {meas }}\left({ }^{0} \mathrm{C}\right)$ & 41 & & & \\
\hline
\end{tabular}

Table 3: Result analysis for 13:00PM Time stamp

\begin{tabular}{|c|c|c|c|c|}
\hline Time Stamp & \multicolumn{4}{|c|}{$13: 00$} \\
\hline Parameters & $\begin{array}{c}\text { Measure } \\
\text { d }\end{array}$ & $\begin{array}{c}\text { STC } \\
\text { Correcte } \\
\text { d }\end{array}$ & $\begin{array}{c}\% \\
\text { Error }\end{array}$ & $\begin{array}{c}\% \\
\text { Accurac } \\
y\end{array}$ \\
\hline$V_{o c}(V)$ & 20.4 & 20.661 & 4.1 & 95.9 \\
\hline$V_{\max }(V)$ & 16.1 & 13.974 & 25.9 & 74.1 \\
\hline $\mathbf{I}_{\mathrm{sc}}(\mathrm{A})$ & 3.18 & 3.373 & 9.1 & 90.9 \\
\hline$I_{\max }(A)$ & 2.76 & 3.375 & 1 & 99 \\
\hline$P_{\max }\left(W_{p}\right)$ & 44.436 & 47.162 & 27.3 & 72.7 \\
\hline$G_{\text {meas }}\left(W / \mathbf{m}^{2}\right)$ & 626.25 & & & \\
\hline$T_{\text {meas }}\left({ }^{0} \mathrm{C}\right)$ & 48 & & & \\
\hline
\end{tabular}

Table 4: Result analysis for 14:00PM Time stamp

\begin{tabular}{|c|c|c|c|c|}
\hline Time Stamp & \multicolumn{4}{|c|}{ 14:00 } \\
\hline Parameters & Measured & $\begin{array}{c}\text { STC } \\
\text { Corrected } \\
\end{array}$ & \begin{tabular}{|c|}
$\%$ \\
Error
\end{tabular} & $\begin{array}{c}\% \% \\
\text { Accuracy } \\
\end{array}$ \\
\hline$V_{o c}(V)$ & 20.5 & 23.314 & 7.8 & 92.2 \\
\hline$V_{\max }(V)$ & 15.6 & 15.768 & 11.6 & 88.4 \\
\hline $\mathbf{I}_{\mathrm{sc}}(\mathrm{A})$ & 2.3 & 3.507 & 4.9 & 95.1 \\
\hline$I_{\max }(A)$ & 2.14 & 3.335 & 2.2 & 97.8 \\
\hline$P_{\max }\left(W_{p}\right)$ & 33.384 & 52.586 & 14.1 & 85.9 \\
\hline$G_{\text {meas }}\left(W / m^{2}\right)$ & 650 & & & \\
\hline $\mathrm{T}_{\text {meas }}\left({ }^{0} \mathrm{C}\right)$ & 57 & & & \\
\hline
\end{tabular}

\subsection{Result of Proposed method (C Load)}

For DC input, capacitor during charging offers low resistance path and after full charging it offers infinity resistance path to flow of current. It sweeps curve naturally from $\mathrm{I}_{\mathrm{sc}}$ to $\mathrm{V}_{\mathrm{oc}}$. IoT based IVCT is tested on the same time stamp and results are tabulated in Table $5,6,7$. Below results shows that, measured electrical parameters of SPV module using capacitive load based IVCT closely reassembles the reference values. Measured parameters are taken from I-V curve and corrected using STC correction formula. External ADC is used with gain 8 and 3300 samples per second for better resolution of I-V curve trace.

Table 5: Result analysis for 12:00PM Time stamp

\begin{tabular}{|c|c|r|r|r|}
\hline $\begin{array}{c}\text { Time } \\
\text { Stamp }\end{array}$ & \multicolumn{4}{|c|}{$12: 00$} \\
\hline $\begin{array}{c}\text { Paramete } \\
\text { rs }\end{array}$ & Measured & $\begin{array}{c}\text { STC } \\
\text { Correcte } \\
\text { d }\end{array}$ & $\begin{array}{c}\text { \% } \\
\text { Error }\end{array}$ & $\begin{array}{c}\text { \% } \\
\text { Accura } \\
\text { cy }\end{array}$ \\
\hline $\mathbf{V}_{\text {oc }}(\mathbf{V})$ & 20.52 & 21.806 & 1.4 & 98.6 \\
\hline $\mathbf{V}_{\text {max }}(\mathbf{V})$ & 15.292 & 16.251 & 7.7 & 92.3 \\
\hline $\mathbf{I}_{\text {sc }}(\mathbf{A})$ & 3.467 & 3.536 & 3.9 & 96.1 \\
\hline $\mathbf{I}_{\max }(\mathbf{A})$ & 3.12 & 3.182 & 6.7 & 93.3 \\
\hline $\mathbf{P}_{\max }\left(\mathbf{W}_{\mathbf{p}}\right)$ & 47.711 & 51.711 & 13.8 & 86.2 \\
\hline $\begin{array}{c}\mathbf{G}_{\text {meas }} \\
\left(\mathbf{W} / \mathbf{m}^{\mathbf{2}}\right)\end{array}$ & 720 & & & \\
\cline { 1 - 2 } $\left.\mathbf{T}_{\text {meas }} \mathbf{(}^{\mathbf{0}} \mathbf{C}\right)$ & 41 & &
\end{tabular}


Table 6: Result analysis for 13:00PM Time stamp

\begin{tabular}{|c|c|c|c|c|}
\hline Time & \multicolumn{4}{|c|}{$13: 00$} \\
\hline Parameters & Measured & $\begin{array}{c}\text { STC } \\
\text { Corrected } \\
\end{array}$ & $\begin{array}{c}\% \\
\text { Error } \\
\end{array}$ & $\begin{array}{c}\% \\
\text { Accuracy } \\
\end{array}$ \\
\hline$V_{o c}(V)$ & 18.806 & 20.501 & 4.6 & 95.4 \\
\hline$V_{\max }(V)$ & 15.287 & 16.665 & 5.3 & 94.7 \\
\hline $\mathbf{I}_{\mathrm{sc}}(\mathrm{A})$ & 3.4611 & 3.576 & 2.8 & 97.2 \\
\hline$I_{\max }(A)$ & 3.184 & 3.289 & 3.5 & 96.5 \\
\hline$P_{\max }\left(W_{p}\right)$ & 48.674 & 54.811 & 8.7 & 91.3 \\
\hline $\begin{array}{c}\mathbf{G}_{\text {meas }} \\
\left(\mathbf{W} / \mathbf{m}^{2}\right)\end{array}$ & 626.25 & & & \\
\hline$T_{\text {meas }}\left({ }^{0} \mathrm{C}\right)$ & 48 & & & \\
\hline
\end{tabular}

Table 7: Result analysis for 14:00PM Time stamp

\begin{tabular}{|c|c|r|r|r|}
\hline $\begin{array}{c}\text { Time } \\
\text { Stamp }\end{array}$ & \multicolumn{4}{|c|}{$14: 00$} \\
\hline Parameters & Measured & $\begin{array}{c}\text { STC } \\
\text { Corrected }\end{array}$ & $\begin{array}{c}\text { \% } \\
\text { Error }\end{array}$ & $\begin{array}{c}\text { \% } \\
\text { Accuracy }\end{array}$ \\
\hline $\mathbf{V}_{\text {oc }}(\mathbf{V})$ & 18.982 & 21.379 & 0.6 & 99.4 \\
\hline $\mathbf{V}_{\max }(\mathbf{V})$ & 15.252 & 17.178 & 2.4 & 97.6 \\
\hline $\mathbf{I}_{\text {sc }}(\mathbf{A})$ & 3.598 & 3.757 & 2.1 & 97.9 \\
\hline $\mathbf{I}_{\text {max }}(\mathbf{A})$ & 3.381 & 3.531 & 3.5 & 96.5 \\
\hline $\mathbf{P}_{\text {max }}\left(\mathbf{W}_{\mathbf{p}}\right)$ & 51.567 & 60.656 & 1.1 & 98.9 \\
\cline { 1 - 2 } $\begin{array}{c}\mathbf{G}_{\text {meas }} \\
\left(\mathbf{W} / \mathbf{m}^{\mathbf{2}}\right)\end{array}$ & 650 & & & \\
\cline { 1 - 2 } $\left.\mathbf{T}_{\text {meas }} \mathbf{(}^{\mathbf{0}} \mathbf{C}\right)$ & 57 & & &
\end{tabular}

All the entries of measured current voltage, light irradiance and module temperature is uploaded on ThingSpeak IoT platform. This results can be analysed anytime from anywhere. We can program threshold values of individual parameter to initiate alarm or emergency signalling during operation.

7-inch touch screen display of Raspberry Pi 3 B model is used with graphical user interface programmed using python library to ease user handling experience. Raspberry pi 3B model has inbuilt Wi-Fi module which help to connect IVCT to network and share data over cloud or IoT platform wirelessly. Screenshot of uploaded data on ThingSpeak IoT platform is shown in Fig. 8.

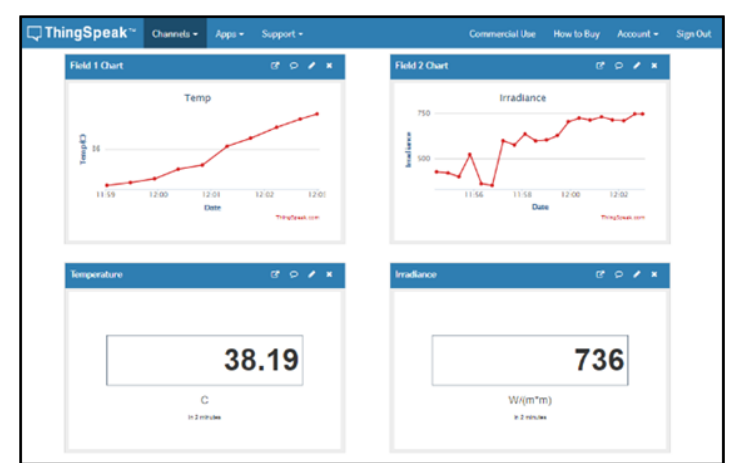

Fig. 8. $G$ and $T_{m}$ data on ThingSpeak IoT Platform

\section{CONCLUSION}

The main circuit is based on a capacitive loading which allow auto sweep of characterisation curves of the solar photovoltaic modules having maximum power up to $60 \mathrm{~W}_{\mathrm{p}}$. The designed IV curve tracer is easily scalable and can trace the I-V curve upto $50 \mathrm{~V}$ open circuit voltage and $10 \mathrm{~A}$ short circuit current. Error in $\mathrm{P}_{\max }$ is upto $15 \%$ due to the impact of error in current measurement. This shows the internal resistive and parasitic effect of components in the circuit while capturing current continuously.

The design and implementation of a low-cost, portable and scalable I-V curve tracer for SPV module is presented in this paper. This device able to examine and monitor SPV modules performances continuously, and it becomes very useful, particularly when the SPV modules are installed at the rooftop or in a rural area. IoT capability of designed IV curve tracer helps to speed-up data capturing, monitoring and subsequent analyses of SPV power plant from a remote location. The bidirectional communication capability of IoT will help to tackle emergency situation easily and will also help to take necessary measures to reduce power/energy losses. Analysis of data on the cloud help to schedule maintenance and reduces the O\&M cost drastically.

\section{ACKNOWLEDGEMENT}

This research did not receive any specific grant from funding agencies in the state, commercial, or non-commercial sectors. Nonetheless, the authors would like to thank the Department of Electronics and Telecommunication Engineering, Symbiosis Institute of Technology, Symbiosis International (Deemed University), Pune, Maharashtra, India for providing the space to set up the Solar Photovoltaics laboratory.

\section{References}

1. B. Shivakumar, and K. Sudhakar, Performance evaluation of $10 \mathrm{MW}$ grid connected solar photovoltaic power plant in India, Energy Reports, 1, 184-192 (2015).

2. A. Sulaiman, F. Inambao, and G. Bright, Solar Energy as an Alternative Energy Source to Power Mobile Robots, Advances in Intelligent Systems and Computing, 274, 957-969 (2014).

3. E. Kandemir, N. S. Cetin, and S. Borekci, A comprehensive overview of maximum power extraction methods for PV systems, Renewable and Sustainable Energy Reviews, 78, 93-112 (2017).

4. F. J. Vorster, and E. E. Van Dyk, Current-voltage characteristics of high-concentration, photovoltaic arrays, Progress in Photovoltaics: Research and Applications, 13(1), 55-66 (2005).

5. S. Fadhel, C. Delpha, D. Diallo, I. Bahri, A. Migan, M. Trabelsi, and M. F. Mimouni, PV shading fault detection and classification based on I-V curve using principal component analysis, Application to isolated PV system. Solar Energy, 179, 1-10 (2019). 
6. S. Sarikh, M. Raoufi, A. Bennouna, A. Benlarabi, and B. Ikken, Photovoltaic system fault identification methodology based on I-V characteristics analysis, AIP Conference Proceedings, 2123(1), 0200371-02003714 (2019).

7. M. R. Maghami, H. Hizam, C. Gomes, M. A. Radzi, M. I. Rezadad, and S. Hajighorbani, Power loss due to soiling on solar panel : A review, Renewable and Sustainable Energy Reviews, 59, 1307-1316 (2016).

8. E. L. Meyer, and E. E. van Dyk, Assessing the reliability and degradation of photovoltaic module performance parameters, IEEE Transactions on Reliability, 53(1), 83-92 (2004).

9. H. Ibrahim, and N. Anani, Variations of PV module parameters with irradiance and temperature, Energy Procedia, 134, 276-285 (2017).

10. H. B. Chi, M. F. N. Tajuddin, N. H. Ghazali, A. Azmi, and M.U. Maaz, Internet of things (IoT) based iv curve tracer for photovoltaic monitoring systems, Indonesian Journal of EE\&CS, 13(3), 1022-1030 (2019).

11. E. Q. B. Macabebe, C. J. Sheppard, and E. E. Van Dyk, Parameter extraction from I-V characteristics of PV devices, Solar Energy, 85(1), 12-18 (2011).

12. Y. Erkaya, H. S. Illa, C. Conway, S. Dhali, and S. Marsillac, Development of a string level fault detection system for solar tracking applications, IEEE 40th Photovoltaic Specialists Conference (2014).

13. M. M. Mahmoud, Transient analysis of a PV power generator charging a capacitor for measurement of the I-V characteristics, Renewable Energy, 31(13), 2198-2206 (2006).

14. S. Filippo, J. Ahmad, A. Ciocia, P. Di Leo, A. F. Murtaza, and M. Chiaberge, Capacitor charging method for $\mathrm{I}-\mathrm{V}$ curve tracer and MPPT in photovoltaic systems, Solar Energy, 119, 461-473 (2015).

15. R. Ahmad, F. Murtaza, U. T. Shami, Zulqarnain, and F. Spertino, An MPPT technique for unshaded/shaded photovoltaic array based on transient evolution of series capacitor, Solar Energy, 157, 377-389 (2017).

16. T. H. Warner, and C. H. Cox, A high power currentvoltage curve tracer employing a capacitive load, Solar Cells, 7(1), 175-181 (1982).

17. Y. Erkaya, P. Moses, and S. Marsillac, On-site characterization of PV modules using a portable, MOSFET-based capacitive load, IEEE 43rd Photovoltaic Specialists Conference (2016).

18. E. E. van Dyk, A. R. Gxasheka, and E. L. Meyer, Monitoring current-voltage characteristics and energy output of silicon photovoltaic modules, Renewable Energy, 30(3), 399-411 (2005).

19. E. Duran, M. Piliougine, M. Sidrach-de-Cardona, J. Galan and J. M. Andujar, Different methods to obtain the I-V curve of PV modules : A review, 33rd IEEE Photovoltaic Specialists Conference (2008)

20. A. Q. Malik, and S. J. B. H. Damit, Outdoor testing of single crystal silicon solar cells, Renewable Energy, 28(9), 1433-1445 (2003). 